University of Wollongong

Research Online

Faculty of Social Sciences - Papers (Archive) Faculty of Arts, Social Sciences \& Humanities

$1-1-2017$

The Role of Implicit Beliefs and Achievement Goals as Protective Factors in Youth Sport

Lauren Gardner

University of Wollongong, lag994@uowmail.edu.au

Stewart A. Vella

University of Wollongong, stvella@uow.edu.au

Christopher A. Magee

University of Wollongong, cmagee@uow.edu.au

Follow this and additional works at: https://ro.uow.edu.au/sspapers

Part of the Education Commons, and the Social and Behavioral Sciences Commons

Research Online is the open access institutional repository for the University of Wollongong. For further information contact the UOW Library: research-pubs@uow.edu.au 


\title{
The Role of Implicit Beliefs and Achievement Goals as Protective Factors in Youth Sport
}

\author{
Abstract \\ 2017 ( ) Association for Applied Sport PsychologyThis study explored whether implicit beliefs and $2 \times 2$ \\ achievement goals were related to enjoyment in youth sport over 1 year and whether perceived changes \\ in the coach iathlete relationship moderated these relationships. Indirect and conditional indirect effect \\ analyses were conducted in a sample of 247 regular sport participants (Mage $=13.03$ years). After \\ adjusting for enjoyment at Time 1, incremental beliefs were indirectly related to Time 2 enjoyment via \\ mastery-approach goals. However, this effect was evident only when the coach $i$ athlete relationship was \\ perceived to have deteriorated. Results highlight the protective value of adaptive implicit beliefs and \\ achievement goals in youth sport.

\section{Disciplines} \\ Education | Social and Behavioral Sciences

\section{Publication Details} \\ Gardner, L., Vella, S. \& Magee, C. (2018). The Role of Implicit Beliefs and Achievement Goals as Protective \\ Factors in Youth Sport. Journal of Applied Sport Psychology, 30 (1), 83-95.
}


6

The Role of Implicit Beliefs and Achievement Goals as Protective Factors in Youth

\section{Sport}

(1)

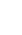

(1)
University of Wollongong, Northfields Avenue, Wollongong, Australia, 2522

${ }^{\text {a }}$ School of Psychology, Faculty of Social Sciences, University of Wollongong, Wollongong NSW 2522, Australia lag994@uowmail.edu.au

${ }^{\mathrm{b}}$ Early Start Research Institute, Faculty of Social Sciences, University of Wollongong, Wollongong NSW 2522, Australia stvella@uow.edu.au

${ }^{\mathrm{c}}$ Centre for Health Initiatives, Faculty of Social Sciences, University of Wollongong, Wollongong NSW 2522, Australia cmagee@uow.edu.au

Correspondence to: Lauren A. Gardner, Building 21, Room 110, University of Wollongong, Northfields Avenue, Wollongong 2522 (e-mail) lag994@uowmail.edu.au

Acknowledgments: This research has been conducted with the support of the Australian Government Research Training Program Scholarship. 


\section{Abstract}

27 This study explored whether implicit beliefs and $2 \times 2$ achievement goals were related to

28 enjoyment in youth sport over a one-year period, and whether perceived changes in the

29 coach-athlete relationship moderated these relationships. Indirect and conditional indirect

30 effect analyses were conducted in a sample of 247 regular sport participants $\left(M_{\text {age }}=13.03\right.$

31 years). After adjusting for enjoyment at Time 1, incremental beliefs were indirectly related to

32 Time 2 enjoyment via mastery-approach goals. However, this effect was only evident when

33 the coach-athlete relationship was perceived to have deteriorated. Results highlight the

34 protective value of adaptive implicit beliefs and achievement goals in youth sport. 
The Role of Implicit Beliefs and Achievement Goals as Protective Factors in Youth Sport

Organized sport is one of the most common types of leisure-time physical activity engaged in by youth worldwide and is particularly prominent within Australia where regular participation rates reach approximately $71-81 \%$ annually (Active Healthy Kids Australia, 2016; Tremblay et al., 2014). Given these large numbers, youth sport can be considered a valuable medium for improving physical and psychosocial health, as well as promoting positive youth development (Eime, Young, Harvey, Charity, \& Payne, 2013; Fraser-Thomas, Côté, \& Deakin, 2005). However, after peaking around the ages of 9-11 years, participation rates decline rapidly which can have adverse consequences for adolescent health and development (Australian Sports Commission, 2016; Balish, McLaren, Rainham, \& Blanchard, 2014). For example, when compared to youth who regularly participate in sport, individuals who drop out of extra-curricular sport show decreased levels of health-related quality of life and have an increased risk of mental health problems (Vella, Cliff, Magee, \& Okely, 2014, 2015). For this reason, research is increasingly focusing on identifying the factors contributing to dropout from organized sport during adolescence. The present research therefore focuses on adolescent sport participants.

Recent research investigating achievement motivation within the sport context has offered some support for a link with future sport participation behavior (Gardner, Vella, \& Magee, 2017). This research indicates that implicit beliefs and achievement goals underlie youth sport participation. Implicit beliefs, originally proposed by Dweck and Leggett (1988) within the social-cognitive model of achievement motivation (SCMAM), refer to an individuals' conceptions about the nature of their ability in a given context (e.g., sport). Individuals who believe their ability is malleable and can be developed through practice are 
said to endorse incremental beliefs, whereas individuals who believe their ability is fixed or innate are said to endorse entity beliefs.

Within the SCMAM, implicit beliefs are considered to be the antecedents of two achievement goals, known as mastery and performance goals, which in turn influence one's cognitive, affective, and behavioral response patterns (Dweck \& Leggett, 1988). Incremental beliefs orient individuals towards mastery goals which are characterized by a focus on learning and self-referenced improvement. Entity beliefs orient individuals towards performance goals which are characterized by a focus on normative displays of competence (Dweck \& Elliot, 1983). Research in a variety of achievement contexts has linked incremental beliefs and mastery goals with more adaptive response patterns (e.g., increased motivation, enjoyment, and persistence at challenging tasks), whereas entity beliefs and performance goals have tended to be associated with more maladaptive response patterns (Biddle, Wang, Chatzisarantis, \& Spray, 2003; Dweck \& Leggett, 1988).

More recently, Cury, Elliot, Da Fonseca, and Moller (2006) proposed a revised version of the SCMAM (r-SCMAM) in response to mixed findings that linked performance goals with negative outcomes (e.g., reduced intrinsic motivation) in some studies and positive outcomes (e.g., enhanced intrinsic motivation) in other studies (Elliot, 1997). The r-SCMAM proposes that the initial dichotomous achievement goal framework be replaced with the $2 \times 2$ achievement goal framework. The $2 \times 2$ achievement goal framework builds on the previous mastery-performance goal distinction by incorporating a further approach-avoidance distinction. Approach goals focus on the possibility of achieving or displaying competence, whereas avoidance goals focus on the potential demonstration of incompetence and the need to avoid it (Elliot \& McGregor, 2001). Gardner et al. (2017) found some cross-sectional support for the utility of the added $2 \times 2$ framework in youth sport participation research, as their results indicated that incremental beliefs were associated with enjoyment and intention 
to continue indirectly through mastery-approach goals. In contrast, entity beliefs were associated with lower enjoyment indirectly through performance-avoidance goals. Gardner, Vella, and Magee (2016) proposed further revisions to the previous SCMAM and r-SCMAM to specifically explore youth sport participation and dropout. Although similarly highlighting the role of implicit beliefs and achievement goals, this model incorporates the role of key social relationships. The push for the inclusion of key social figures is particularly important in this context given that multiple levels of factors (e.g., intrapersonal, interpersonal, institutional etc.) have been implicated in youth sport participation and dropout (Balish et al., 2014; Crane \& Temple, 2015). It is proposed that perceptions of relationships with key social figures (e.g., coaches, parents, and peers) could moderate the effects of implicit beliefs and achievement goals on outcomes (Gardner, Vella, et al., 2016). Consideration of social figures is also consistent with calls in the implicit belief literature for potential moderators to be examined (Vella, Braithewaite, Gardner, \& Spray, 2016). Although both implicit beliefs/achievement goals and key social factors have been independently associated with indicators of sport participation and dropout behavior, research has not yet examined the potential interactive effects in this way (Gardner, Magee, \& Vella, 2016; Gardner et al., 2017).

Coaches could be a particularly important social figure to consider in the context of youth sport. Positive coach-athlete relationships have consistently been linked with adaptive outcomes in sport, including sustained participation (Gardner, Magee, et al., 2016; Gould, Collins, Lauer, \& Chung, 2007; Rottensteiner, Konttinen, \& Laakso, 2015). According to Jowett's (2007) 3+1Cs model, high quality coach-athlete relationships are based on closeness (e.g., feelings of trust and mutual respect), complementarity (e.g., responsiveness and cooperation), commitment (e.g., planning to maintain a strong relationship), and coorientation (e.g., shared views and mutual understanding). Although parents and peers also 
play an important role in youth sport participation, research suggests that coaches may be more strongly linked to enjoyment and may even compensate for other less supportive relationships (Gardner, Magee, et al., 2016; Scanlan, Carpenter, Lobel, \& Simons, 1993). Moreover, there is experimental evidence that changes in coach behaviors can affect athlete outcomes such as self-esteem, enjoyment, and dropout (Eime et al., 2013; Langan, Blake, \& Lonsdale, 2013). Although it has not yet been investigated, it is plausible that changes in the coach-athlete relationship over time moderate the relationship between implicit beliefs and outcomes.

The present research aims to explore the relationships among implicit beliefs, achievement goals, and perceived changes in the coach-athlete relationship over a one-year period. In line with previous research (e.g., Gardner et al., 2017), enjoyment will be used as an indicator of future sport participation behavior given its identification as the most commonly reported reason for continued participation or dropout (Crane \& Temple, 2015). Consistent with previous cross-sectional findings, it is hypothesized that incremental beliefs and mastery-approach goals will lead to greater enjoyment after one-year, whereas entity beliefs and performance-avoidance goals will lead to lower enjoyment after one-year. Although previously unexplored, it is expected that changes in the coach-athlete relationship will predict enjoyment over the one-year period and moderate the relationships between implicit beliefs, achievement goals, and enjoyment. Specifically, improvements in the coachathlete relationship are hypothesized to buffer the negative influence of maladaptive implicit beliefs and achievement goals (entity beliefs and performance-avoidance goals) on enjoyment. In contrast, a coach-athlete relationship that has deteriorated may weaken the positive effects of adaptive implicit beliefs and achievement goals (incremental beliefs and mastery-approach goals) on enjoyment. Given the varying role of perceived competence within both the SCMAM and the r-SCMAM, and consistent with previous research, 
perceived competence will be included as a covariate in all analyses (Gardner et al., 2017).

Other potentially confounding factors that will be included as covariates include: age, sex, and perceptions of parental and peer relationships (Balish et al., 2014; Gardner, Vella, et al., 2016; Vella, Cliff, \& Okely, 2014).

\section{Method}

\section{Participants and Procedures}

Participants in this study were recruited from two private high schools in Sydney, Australia. A total of 393 students (94 males, 299 females) were initially recruited and completed a written questionnaire during their regular Physical Education lesson at school. Of the 393 students, 327 students (77 males, 250 females; $M_{\text {age }}=13.03, S D=.84$ ) reported regular participation in organized extracurricular sport and provided responses to a battery of questionnaires with respect to the sport they considered to be their main sport. These students were invited to participate in a follow-up questionnaire 12 months later, with data collected from 273 sport participants (83.5\% study retention rate) aged between 11 and 15 years (62 males, 211 females; $\left.M_{a g e}=13.01, S D=.83\right)$ at baseline. Two hundred and forty-seven participants (90\%; 54 males, 193 females) reported continued participation in their main sport, whereas 26 (10\%; 8 males, 18 females) reported that they had dropped out of their main sport. Only participants who reported continued participation in their main sport, and thus completed all measures regarding the same sport at both time points, were included in the study. Approval for the study was gained via the institutional research ethics committee.

\section{Measures}

Implicit Beliefs. The Conceptions of the Nature of Athletic Ability QuestionnaireVersion 2 (CNAAQ-2; Biddle et al., 2003) was used to measure implicit incremental and entity beliefs about athletic ability. The instrument includes 12 items, which are scored in relation to four subscales. Incremental beliefs were assessed through the Learning subscale 
159 (e.g., "You need to learn and to work hard to be good at sport") and the Improvement 160 subscale (e.g., "How good you are at sport will always improve if you work at it"). Entity

161 beliefs were assessed through the Stable subscale (e.g., "Even if you try, the level you reach in sport will change very little") and the Gift subscale (e.g., "To be good at sport you need to be naturally gifted"). Responses were given on a 5-point scale ranging from 1 (strongly disagree) to 5 (strongly agree). This questionnaire has been found to have adequate reliability and validity in youth populations (Biddle et al., 2003). In the current study, the Cronbach's alpha for the subscales ranged from $.66-.70$.

Achievement Goals. Achievement goals were assessed using the Achievement Goals Questionnaire for Sport (AGQ-S; Conroy, Elliot, \& Hofer, 2003). The instrument consists of 12 items assessing mastery-approach goals (e.g., "It is important to me to perform as well as I possibly can"), mastery-avoidance goals (e.g., "Sometimes I'm afraid that I may not perform as well as I'd like"), performance-approach goals (e.g., "My goal is to do better than most other performers"), and performance avoidance goals (e.g., "I just want to avoid performing worse than others"). Responses were given on a 7-point scale ranging from 1 (not at all like me) to 7 (completely like me). The psychometric properties have been supported in youth sport populations (Conroy et al., 2003). Cronbach's alpha for the four subscales ranged from $.70-.84$

Coach-Athlete Relationship Quality. Perceived quality of the coach-athlete relationship was assessed using the Coach-Athlete Relationship Questionnaire (CART-Q; Jowett \& Ntoumanis, 2004). The questionnaire consists of 11 items that are scored in relation to three subscales: Closeness (e.g., "I like my coach"), Commitment (e.g., "I feel committed to my coach"), and Complementarity (e.g., "When I am coached by my coach, I am ready to do my best"). Each item includes a seven-point scale ranging from 1 (strongly disagree) to 7 (strongly agree). The subscales were summed to produce an overall coach-athlete 
relationship score. The scales validity and reliability has been demonstrated in the youth sport context (Jowett \& Ntoumanis, 2004). Cronbach's alpha in the current study was $\alpha=.93$ at Time 1 and $\alpha=.96$ at Time 2 .

Enjoyment. Enjoyment in sport was measured using the Enjoyment subscale from the Sport Commitment Model (SCM; Scanlan, Simons, Carpenter, Schmidt, \& Keeler, 1993).

The scale includes four items (e.g., "Do you have fun playing your main sport?") rated on a five-point scale ranging from 1 (not at all) to 5 (very much). Cronbach's alpha in the current study was $\alpha=.95$ at both Time 1 and Time 2 .

Covariates. Variables controlled for in the analyses included participants' age, sex, perceptions of competence, and perceptions of parental support, friendship quality, and peer acceptance as identified in Gardner and colleagues' (2016) proposed motivational model. Perceived competence was assessed using the Athletic Competence subscale of Harter's (1985) Self-Perception Profile for Children $(\alpha=.76)$; parental support was assessed using Van Yperen's (1995) Perceived Parental Support Scale $(\alpha=.77)$; friendship quality in sport was assessed using Weiss and Smith's (1999) Sport Friendship Quality Scale $(\alpha=.90)$; and peer acceptance was assessed using the Social subscale from Harter's (1985) Self-Perception Profile for Children $(\alpha=.83)$.

\section{Statistical Analysis}

To assess change in the perceived quality of the coach-athlete relationship over the one year period, a raw change score was computed by deducting scores at Time 1 from scores at Time 2. Descriptive statistics and bivariate Pearson's correlations were calculated for each of the variables of interest. Linear regression was conducted to explore the link between change in perceived coach-athlete relationship quality and enjoyment at Time 2 after adjusting for enjoyment at Time 1 . 
enjoyment (dependent variable) through achievement goals (mediating variables), while path linking incremental beliefs at Time 1 on Time 2 enjoyment via the two mastery goals was tested controlling for Time 1 enjoyment, entity beliefs, performance-approach goals, performance-avoidance goals, age, sex, perceived competence, parental support, friendship quality, and peer acceptance. Second, the indirect path linking entity beliefs at Time 1 with Time 2 enjoyment via the two performance goals was tested controlling for Time 1 enjoyment, incremental beliefs, mastery-approach goals, mastery-avoidance goals, perceived competence, parental support, friendship quality, and peer acceptance. Both models used a bootstrapping procedure with 5000 resamples to determine the significance of the indirect effects on the basis of $95 \%$ confidence intervals. paths linking Time 1 beliefs to Time 2 enjoyment via goals were moderated by changes in the coach-athlete relationship. Using the approach recommended by Hayes (2013), four conditional indirect path models were tested: incremental beliefs to change in enjoyment via mastery-approach goals; incremental beliefs to change in enjoyment via mastery-avoidance goals; entity beliefs to change in enjoyment via performance-approach goals; entity beliefs to change in enjoyment via performance-avoidance goals. Time 1 enjoyment, age, sex, perceived competence, parental support, friendship quality, peer acceptance, as well as the remaining implicit belief and achievement goals were controlled for in each of the models. A bootstrapping procedure with 5000 resamples was used to determine the significance of the conditional indirect effects on the basis of $95 \%$ confidence intervals at 3 levels of the moderator ( 1 standard deviation below the mean, the mean, and 1 standard deviation above 
the mean). All analyses were conducted using Mplus version 7 (Muthén \& Muthén, 19982012).

\section{Descriptive Statistics}

Descriptive statistics are illustrated in Table 1. Incremental beliefs and masteryapproach goals were positively correlated with enjoyment at both time points, whereas entity beliefs and performance-avoidance goals were negatively correlated with enjoyment at both time points. On average, the sample reported a slight negative change in their perceptions of the coach-athlete relationship over the one-year period. The descriptive statistics are summarized in Table 1. Initial regression analyses indicated that changes in the perceived coach-athlete relationship predicted enjoyment at Time $2, B=.10, p<.001$, after controlling for enjoyment at Time 1, age, sex, incremental beliefs, entity beliefs, mastery-approach goals, mastery-avoidance goals, performance-approach goals, performance-avoidance goals, perceived competence, parental support, friendship quality, and peer acceptance.

\section{Indirect Effects Analyses}

Incremental beliefs and mastery goals. The indirect models indicated that incremental beliefs were positively associated with mastery-approach goals, $(B=.15, p<$ $.001)$, and mastery-avoidance goals, $(B=.14, p=.01)$ after controlling for the covariates listed above. However, neither mastery-approach goals, $(B=.27, p=.07)$, nor masteryavoidance goals, $(B=.01, p=.89)$, were significantly related to Time 2 enjoyment. The direct effect of incremental beliefs on enjoyment was not significant, $(B=-.02, p=.81)$. Incremental beliefs were indirectly associated with Time 2 enjoyment through masteryapproach goals; however, the indirect path linking incremental beliefs with enjoyment through mastery-avoidance goals was not significant. The indirect effects are summarized in Table 2. 
Entity beliefs and performance goals. Entity beliefs were positively associated with

258

259

260

261

262

263

264

265

266

267

268

269

270

271

273

274

performance-approach goals, $(B=.20, p<.001)$, and performance-avoidance goals, $(B=.19$, $p<.001)$ after controlling for the covariates listed above. However, neither performanceapproach goals, $(B=.05, p=.50)$, nor performance-avoidance goals, $(B=-.09, p=.15)$, were significantly related to Time 2 enjoyment. The direct effect of entity beliefs on enjoyment was not significant, $(B=-.14, p=.72)$. The indirect paths linking entity beliefs with Time 2 enjoyment through performance-approach and performance-avoidance goals were not significant. The indirect effects are summarized in Table 2.

\section{Conditional Indirect Effects Analyses}

Table 3 provides a summary of the conditional indirect effect results at low (one standard deviation below the mean; -15), average (the mean; -2.07), and high (one standard deviation above the mean; 10.86) levels of the moderator for each model. After adjusting for enjoyment at Time 1, significant conditional indirect effects emerged in the model linking incremental beliefs with Time 2 enjoyment through mastery-approach goals. Changes in perceptions of the coach-athlete relationship significantly moderated the indirect effects at both one standard deviation below the mean and the mean. There was no significant conditional indirect effect at one standard deviation above the mean. Therefore, the indirect effect of mastery-approach goals in the relationship between incremental beliefs and enjoyment became stronger as the coach-athlete relationship deteriorated. There were no significant conditional indirect effects for any of the remaining models.

\section{Discussion}

This study examined whether implicit beliefs and achievement goals were related to enjoyment in youth sport over a one-year period, and whether changes in the perceived coach-athlete relationship moderated these relationships. In partial support of our hypotheses, incremental beliefs were indirectly related to greater enjoyment through mastery-approach 
goals. This suggests that the belief that ability can be increased and developed through practice, may be related to greater enjoyment due to a focus on demonstrating self-referenced mastery of skills. Perceived change in the quality of the coach athlete relationship predicted enjoyment at one-year follow up. However, the indirect effect of incremental beliefs on enjoyment through mastery-approach goals was only evident when the coach-athlete relationship was perceived to have deteriorated. This novel finding may reflect the protective value of adaptive implicit beliefs and achievement goals in the youth sport context. No other indirect or conditional indirect effects were found.

The finding that incremental beliefs were linked with greater enjoyment via masteryapproach goals is consistent with theoretical expectations and previous cross-sectional youth sport research (Cury et al., 2006; Gardner et al., 2017). However, contrary to expectations, there was no indirect effect of performance-avoidance goals in the relationship between entity beliefs and enjoyment. Given that entity beliefs were expected to be associated with a reduction in enjoyment, this may be due to the sample reporting high levels of enjoyment at both time points. It may also reflect a common issue in youth sport research where the associations between entity beliefs and outcomes are weaker relative to incremental beliefs (Vella et al., 2016). This may be because the effects of implicit beliefs are more prominent during times of adversity which may not be as common within voluntary sport, as compared to other non-voluntary contexts, such as school (Dweck, 1999).

There were also no indirect effects present through mastery-avoidance or performance-approach goals. Although this is consistent with previous research identifying the strongest links between incremental beliefs/mastery-approach goals and entity beliefs/performance-avoidance goals (Gardner et al., 2017; Stenling, Hassmén, \& Holmström, 2014; Stevenson \& Lochbaum, 2008), the findings raise questions regarding whether the inclusion of all four achievement goals is necessary. Rather, the findings may be 
lending more support to a dichotomous framework, similar to Dweck and Leggett's (1988) original proposal. More research is needed on the $2 \times 2$ achievement goal framework to better understand the role and significance of mastery-avoidance and performance-approach goals in the youth sport context.

The link between change in perceptions of the coach-athlete relationship and enjoyment over the one-year period is in line with previous research highlighting the importance of the coach for enjoyment and continued participation in youth sport (Gardner, Magee, et al., 2016; Gould et al., 2007; Rottensteiner et al., 2015). The finding that the indirect relationship between implicit beliefs and enjoyment via mastery-approach goals was only significant when the perceived coach-athlete relationship deteriorated demonstrates the value of endorsing incremental beliefs and mastery-approach goals. Given most studies exploring the SCMAM are cross-sectional in nature, this finding adds to our current understanding of implicit beliefs and achievement goals, and provides new information about the interactive effect of the social environment over time. The finding suggests that, even when this key relationship is declining, individuals can fall back on their adaptive implicit beliefs and achievement goals to sustain their enjoyment and participation. Research investigating implicit beliefs in the personality domain found that during times of social adversity, adolescents endorsing incremental beliefs had less negative reactions (e.g., shame, aggression, stress) than those endorsing entity beliefs (Yeager et al., 2014). Although this research was conducted in the school setting with a focus on peer relationships, it is feasible that implicit beliefs set up an interpretive framework that guides responses in a range of areas, including sport. It may not be until the individuals are experiencing difficulties with their social relationships that we are able to see the protective value of their adaptive implicit beliefs and achievement goals. 
of the other models, we cannot overstate these findings and must acknowledge the numerous

other variables that can influence levels of youth sport enjoyment and participation over time.

For example, some of these may include conflict between other sport or non-sport activities, over-training and burnout, injuries, time and financial costs, parental pressure or overinvolvement, an overemphasis on winning, and difficulty accessing facilities (Balish et al., 2014; Crane \& Temple, 2015).

\section{Theoretical and Practical Implications}

The present research aimed to explore the links between implicit beliefs, achievement goals, and outcomes based on Dweck and Leggett's (1988) original SCMAM, Cury et al.'s (2006) r-SCMAM, and Gardner, Vella et al.'s (2016) subsequent adaptation for understanding youth sport participation and enjoyment. The findings provide support for the notion that adaptive implicit beliefs and achievement goals lead to positive outcomes; however, there was less support for the role of entity beliefs and performance goals. Findings provide some support for the inclusion of the approach-avoidance distinction, although as previously mentioned, this remains a contentious issue given the continued uncertainty surrounding the role of mastery-avoidance and performance-approach goals. Additionally, given perceived competence was only included as a covariate, its role within the model requires further exploration. For example, future research should investigate whether perceived competence plays a moderating role between achievement goals and outcomes (as proposed in the r-SCMAM).

Although the proposed addition of key social figures as moderating factors was partially supported, the nature of these effects was not strong or in the hypothesized direction. 
participation and should be considered in addition to the cognitive factors in the model.

Future research should also explore the role of other key social relationships, including those with parents and peers. One such avenue of investigation may include exploring the role of social goals within the model. Similar to achievement goals which view competence as the primary motive of behavior, social goals view the desire for social connections as the central motive of behavior in sport (Allen, 2003). Allen (2005) identified three types of social goals individuals might pursue in sport: affiliation goals (focus on developing reciprocal relationships), recognition goals (focus on gaining recognition from others for effort or ability), and status goals (focus on gaining popularity). Social affiliation goals are considered intrinsic and have been linked with more adaptive outcomes including greater interest and enjoyment in sport (Allen, 2003). In contrast, recognition and status goals rely on extrinsic validation and may produce maladaptive outcomes if validation is not received (Hodge, Allen, \& Smellie, 2008). Understanding the type of social goals individuals are pursuing may therefore help to further explain individuals' response patterns, particularly during times of social adversity.

In a practical sense, the findings highlight the protective value of incremental beliefs and mastery-approach goals and the need to facilitate them among youth sport participants. Researchers should target younger age groups so they are equipped to interpret and respond adaptively as they progress through the adolescent years which are often associated with social difficulties and stress (Fraser-Thomas et al., 2005). Previous research has demonstrated the successful adjustment of adolescent's implicit beliefs about athletic ability (Spray, Wang, Biddle, Chatzisarantis, \& Warburton, 2006), however it is unknown how long these manipulation effects can last. Given the primary role of the coach and their frequent interaction with sport participants, it is feasible that regularly promoting incremental beliefs and mastery-approach goals could have lasting effects. Vella, Cliff, Okely, Weintraub, and 
Robinson (2014) identified six instructional strategies coaches can use to promote incremental beliefs. These include focusing on effort and persistence (e.g., through rewards and feedback), providing challenge (e.g., through moderately difficult tasks or goal setting), exploring the value of setbacks (e.g., by facilitating reflection and problem solving), promoting self-referenced learning and a mastery climate (e.g., avoiding normative comparisons), providing high performance expectations (e.g., encouraging athletes to improve) and emphasizing the definition of success as giving best efforts. Coach education programs could aid coaches in understanding the need to facilitate adaptive implicit beliefs and achievement goals and provide information on how to implement these strategies.

Parents could also influence the types of implicit beliefs and achievement goals adolescents adopt, particularly given the greater amount of time they spend with the youth sport participant. It is argued that the way that parents respond to their child's achievement related behavior (e.g., through praise or criticism) can shape their achievement motivation in a range of contexts (Dweck, 1999). To encourage appropriate and supportive parenting in sport, rules and campaigns such as "Silent Saturdays" and "Play by the Rules" have been introduced (Active Healthy Kids Australia, 2016). However, parents need to be informed about the implications of their behaviors at all times, including those away from the sporting field (Elliott \& Drummond, 2017). Parent education programs could teach parents the value of adaptive implicit beliefs and achievement goals for their child's development and provide them with strategies to promote them. For example, post-game debriefs should include recognition of improvements based on their previous skill level, avoiding comparing their performance to others', and encouraging practice for further improvements. Furthermore, parents need to be aware of the way they convey their own achievement motivation to their children, as research has linked youth sports participants' perceptions of their parents' achievement orientations with the development of their own achievement orientations 
406 (Weigand, Carr, Petherick, \& Taylor, 2001). This is particularly important during late

407 childhood when children begin to differentiate between effort and ability, and are therefore

408

409

410

411

412

413

414

415

416

417

418

419

420

421

422

423

424

425

426

427

428

429

430

susceptible to developing a maladaptive achievement orientation (Nicholls, 1984).

\section{Strengths and Limitations}

Limitations of the study include the low number of individuals who dropped out of sport which led to the use of enjoyment as a proxy measure of dropout. Although enjoyment is considered the most common reason for continued participation and dropout (Crane \& Temple, 2015), the results may have been skewed by only including regular sport participants. As is common in youth sport research, participants tended to report very high levels of enjoyment, incremental beliefs, and mastery-approach goals which may produce ceiling effects (Stenling et al., 2014). The low rate of dropout in the sample may be due to recruiting participants from private high schools. These students are generally from higher socioeconomic positions which is an established predictor of sport participation (Vella, Cliff, \& Okely, 2014). Future studies should recruit larger sample sizes from a range of socioeconomic positions to enable the investigation of individuals who have dropped out of sport. Given the effects of implicit beliefs are expected to be most apparent during times of adversity, this may allow us to better explore the role of entity beliefs/performance goals in conjunction with social relationships.

Other limitations include the failure to measure the length of the coach-athlete relationship and track whether the coaches remained the same from Time 1 to Time 2 . This may be particularly important as there tends to be a high rate of turnover of youth sport coaches (O'Connor \& Bennie, 2006). Future studies should therefore measure and control for these factors. The research also focused on sport participants within a narrow age range where dropout is already an established issue. Research may benefit from focusing on younger participants with the aim of preventing dropout before it occurs. Finally, there were a 
large number of females as compared to males in the sample. Future research should aim to use larger samples consisting of more even numbers of males and females. This would lead to more generalizable findings and would allow researchers to explore whether the relationships among implicit beliefs, achievement goals, and key social figures vary based on sex.

Strengths of the research include the use of a prospective design which allowed us to explore perceptions of the coach-athlete relationship and enjoyment over time. The study addressed a need for research to further explore potential moderating variables in the relationship between implicit beliefs and outcomes (Gardner, Vella, et al., 2016; Vella et al., 2016), and was the first to consider the coach in this way. The inclusion of other key social variables (parental and peer relationships) as covariates in all analyses also strengthened the research.

\section{Conclusion}

This study revealed that the belief that ability is malleable and can be improved through practice (i.e., incremental beliefs) is related to greater levels of enjoyment, in part due to a focus on achieving self-referenced mastery (i.e., mastery-approach goals). Perceived change in the quality of the coach-athlete relationship was also related to enjoyment over the one-year period. When individuals perceived deterioration in the quality of the coach-athlete relationship, the indirect effect of mastery-approach goals on the relationship between incremental beliefs and enjoyment was stronger. This highlights the protective value of adaptive implicit beliefs and achievement goals in youth sport. These findings could have important implications for sport participants during times of social adversity. Researchers and sports organizations should aim to educate coaches and parents on the significance of incremental beliefs and mastery-approach goals for positive development and provide them with strategies to facilitate these adaptive implicit beliefs and achievement goals in youth sports participants. 


\section{References}

457

458

459

460

461

462

463

464

465

466

467

468

469

470

471

472

473

474

475

476

477

478

479

480

Active Healthy Kids Australia. (2016). Physical literacy: Do our kids have all the tools? 2016 report card on physical activity for children and young people. Australia: Retrieved from http://www.activehealthykidsaustralia.com.au/report-cards/.

Allen, J. B. (2003). Social motivation in youth sport. Journal of Sport \& Exercise Psychology, 25, 551-567.

Allen, J. B. (2005). Measuring social motivational orientations in sport: An examination of the construct validity of the SMOSS. International Journal of Sport \& Exercise Psychology, 3, 147-161.

Australian Sports Commission. (2016). AusPlay participation data for the sport sector: Summary of key national findings. Canberra, Australia: Retrieved from http://www.ausport.gov.au/information/ausplay.

Balish, S. M., McLaren, C., Rainham, D., \& Blanchard, C. (2014). Correlates of youth sport attrition: A review and future directions. Psychology of Sport and Exercise, 15, 429439. doi: 10.1016/j.psychsport.2014.04.003

Biddle, S. J. H., Wang, C. K. J., Chatzisarantis, N. L. D., \& Spray, C. M. (2003). Motivation for physical activity in young people: Entity and incremental beliefs about athletic ability. Journal of Sports Sciences, 21, 973-989. doi:

$10.1080 / 02640410310001641377$

Conroy, D. E., Elliot, A. J., \& Hofer, S. M. (2003). A 2 X 2 achievement goals questionnaire for sport: Evidence for factorial invariance, temporal stability, and external validity. Journal of Sport \& Exercise Psychology, 25, 456-476.

Crane, J., \& Temple, V. (2015). A systematic review of dropout from organized sport among children and youth. European Physical Education Review, 21, 114-131. doi: $10.1177 / 1356336 \times 14555294$ 
Cury, F., Elliot, A. J., Da Fonseca, D., \& Moller, A. C. (2006). The social-cognitive model of achievement motivation and the $2 \times 2$ achievement goal framework. Journal of Personality and Social Psychology, 90, 666-679. doi: 10.1037/0022-3514.90.4.666

Dweck, C. S. (1999). Self-theories: Their role in motivation, personality, and development. Philadelphia, PA: Psychological Press.

Dweck, C. S., \& Elliot, E. S. (1983). Achievement Motivation. In P. Mussen \& E. M. Hetherington (Eds.), Handbook of child psychology (pp. 643-691). New York, NY: Wiley.

Dweck, C. S., \& Leggett, E. L. (1988). A social-cognitive approach to motivation and personality. Psychological Review, 95, 256-273. doi: 10.1037/0033-295X.95.2.256

Eime, R. M., Young, J. A., Harvey, J. T., Charity, M. J., \& Payne, W. R. (2013). A systematic review of the psychological and social benefits of participation in sport for children and adolescents: Informing development of a conceptual model of health through sport. The International Journal of Behavioral Nutrition and Physical Activity, 10, 1-21. doi: 10.1186/1479-5868-10-98

Elliot, A. J. (1997). Integrating the "classic" and "contemporary" approaches to achievement motivation: A hierarchical model of approach and avoidance achievement motivation. In M. Maehr \& P. Pintrich (Eds.), Advances in motivation and achievement (Vol. 10, pp. 143-179). Greenwich, CT: JAI Press.

Elliot, A. J., \& McGregor, H. A. (2001). A 2 x 2 achievement goal framework. Journal of Personality and Social Psychology, 80, 501-519.

Elliott, S. K., \& Drummond, M. J. N. (2017). Parents in youth sport: what happens after the game? Sport, Education and Society, 22, 391-406. doi: $10.1080 / 13573322.2015 .1036233$ 
505

506

507

508

509

510

511

512

513

514

515

516

517

518

519

520

521

522

523

524

525

526

527

528

529

Fraser-Thomas, J., Côté, J., \& Deakin, J. (2005). Youth sport programs: An avenue to foster positive youth development. Physical Education and Sport Pedagogy, 10, 19-40. doi: $10.1080 / 1740898042000334890$

Gardner, L. A., Magee, C. A., \& Vella, S. A. (2016). Social climate profiles in adolescent sports: Associations with enjoyment and intention to continue. Journal of Adolescence, 52, 112-123. doi: http://dx.doi.org/10.1016/j.adolescence.2016.08.003

Gardner, L. A., Vella, S. A., \& Magee, C. A. (2016). A motivational model to understand youth sport dropout and enjoyment. International Journal of Sport Psychology, 47, 203-223.

Gardner, L. A., Vella, S. A., \& Magee, C. A. (2017). Continued Participation in Youth Sports: The Role of Achievement Motivation. Journal of Applied Sport Psychology, 29, 17-31. doi: 10.1080/10413200.2016.1173744

Gould, D., Collins, K., Lauer, L., \& Chung, Y. (2007). Coaching life skills through football: A study of award winning high school coaches. Journal of Applied Sport Psychology, 19, 16-37. doi: 10.1080/10413200601113786

Harter, S. (1985). Manual for the self-perception profile for children. Denver: University of Denver.

Hayes, A. F. (2013). Introduction to mediation, moderation, and conditional process analyses: A regression-based approach. New York, NY: The Guilford Press.

Hodge, K., Allen, J. B., \& Smellie, L. (2008). Motivation in Masters sport: Achievement and social goals. [Article]. Psychology of Sport \& Exercise, 9, 157-176. doi: 10.1016/j.psychsport.2007.03.002

Jowett, S., \& Ntoumanis, N. (2004). The coach-athlete relationship questionnaire (CART-Q): Development and initial validation. Scandinavian Journal of Medicine \& Science in Sports, 14, 245-257. doi: 10.1046/j.1600-0838.2003.00338.x 
530

531

532

533

534

535

536

537

538

539

540

541

542

543

544

545

546

547

548

549

550

551

552

553

Jowett, S. (2007). Interdependence analysis and the $3+1 \mathrm{Cs}$ in the coach-athlete relationship. In S. Jowett \& D. Lavallee (Eds.), Social psychology in sport (pp. 15-77). New York, NY: Routledge.

Langan, E., Blake, C., \& Lonsdale, C. (2013). Systematic review of the effectiveness of interpersonal coach education interventions on athlete outcomes. Psychology of Sport and Exercise, 14, 37-49. doi: http://dx.doi.org/10.1016/j.psychsport.2012.06.007

Muthén, L. K., \& Muthén, B. O. (1998-2012). Mplus Users Guide. Seventh Edition. Los Angeles, CA: Muthén \& Muthén.

Nicholls, J. G. (1984). Achievement motivation: Conceptions of ability, subjective experience, task choice, and performance. Psychological Review, 91, 328-346. doi: 10.1037/0033-295x.91.3.328

O'Connor, D., \& Bennie, A. (2006). The retention of youth sport coaches. Change : Transformations in Education, 9, 27-38.

Rottensteiner, C., Konttinen, N., \& Laakso, L. (2015). Sustained participation in youth sports related to coach-athlete relationship and coach-created motivational climate. International Sport Coaching Journal, 2, 29-38.

Scanlan, T. K., Carpenter, P. J., Lobel, M., \& Simons, J. P. (1993). Sources of enjoyment for youth sport athletes. Pediatric Exercise Science, 5, 275-285.

Scanlan, T. K., Simons, J. P., Carpenter, P. J., Schmidt, G. W., \& Keeler, B. (1993). The Sport Commitment Model: Measurement development for the youth-sport domain. Journal of Sport \& Exercise Psychology, 15, 16-38.

Spray, C. M., Wang, C. K. J., Biddle, S. J. H., Chatzisarantis, N. L. D., \& Warburton, V. E. (2006). An experimental test of self-theories of ability in youth sport. Psychology of Sport \& Exercise, 7, 255-267. doi: 10.1016/j.psychsport.2005.05.001 
554 Stenling, A., Hassmén, P., \& Holmström, S. (2014). Implicit beliefs of ability, approach-

555

556

557

558

559

560

561

562

563

564

565

566

567

568

569

570

571

572

573

574

575

576

577 avoidance goals and cognitive anxiety among team sport athletes. European Journal of Sport Science, 14, 720-729. doi: 10.1080/17461391.2014.901419

Stevenson, S. J., \& Lochbaum, M. R. (2008). Understanding exercise motivation: Examining the revised social-cognitive model of achievement motivation. Journal of Sport Behavior, 31, 389-412.

Tremblay, M. S., Gray, C. E., Akinroye, K. K., Harrington, D. M., Katzmarzyk, P. T., Lambert, E. V., .. . Tomkinson, G. R. (2014). Physical activity of children: A global matrix of grades comparing 15 countries. Journal of Physical Activity and Health, 11, S113-S125. doi: http://dx.doi.org/10.1123/jpah.2014-0177

Van Yperen, N. W. (1995). Interpersonal stress, performance-level, and parental support: A longitudinal-study among highly skilled young soccer players. Sport Psychologist, 9, 225-241.

Vella, S. A., Braithewaite, R. E., Gardner, L. A., \& Spray, C. M. (2016). A systematic review and meta-analysis of implicit theory research in sport, physical activity, and physical education. International Review of Sport and Exercise Psychology, 9, 191-214. doi: 10.1080/1750984x.2016.1160418

Vella, S. A., Cliff, D. P., Magee, C. A., \& Okely, A. D. (2014). Sports participation and parent-reported health-related quality of life in children: Longitudinal associations. The Journal of Pediatrics, 164, 1469-1474. doi: 10.1016/j.jpeds.2014.01.071

Vella, S. A., Cliff, D. P., Magee, C. A., \& Okely, A. D. (2015). Associations between sports participation and psychological difficulties during childhood: A two-year follow up. Journal of Science and Medicine in Sport, 18, 304-309. doi:

10.1016/j.jsams.2014.05.006 
578 Vella, S. A., Cliff, D. P., \& Okely, A. D. (2014). Socio-ecological predictors of participation

579

580

581

582

583

584

585

586

587

588

589

590

591

592 and dropout in organised sports during childhood. International Journal of Behavioral Nutrition and Physical Activity, 11, 62-71. doi: 10.1186/1479-5868-11-62

Vella, S. A., Cliff, D. P., Okely, A. D., Weintraub, D. L., \& Robinson, T. N. (2014). Instructional strategies to promote incremental beliefs in youth sport. Quest, 66, 357370. doi: 10.1080/00336297.2014.950757

Weigand, D. A., Carr, S., Petherick, C., \& Taylor, A. (2001). Motivational climate in sport and physical education: The role of significant others. European Journal of Sport Science, 1,1 .

Weiss, M. R., \& Smith, A. L. (1999). Quality of youth sport friendships: Measurement development and validation. Journal of Sport \& Exercise Psychology, 21, 145-166.

Yeager, D. S., Johnson, R., Spitzer, B. J., Trzesniewski, K. H., Powers, J., \& Dweck, C. S. (2014). The far-reaching effects of believing people can change: Implicit theories of personality shape stress, health, and achievement during adolescence. Journal of Personality and Social Psychology, 106, 867-884. doi: 10.1037/a0036335 